\title{
Reduced Orexin System Function Contributes to Resilience to Repeated Social Stress
}

\author{
(DLaura A. Grafe, ${ }^{1}$ D. Darrell Eacret, ${ }^{1}$ Jane Dobkin, ${ }^{2}$ and Seema Bhatnagar ${ }^{1,2}$
}

DOI:http://dx.doi.org/10.1523/ENEURO.0273-17.2018

${ }^{1}$ Department of Anesthesiology and Critical Care, Children's Hospital of Philadelphia, Philadelphia, Pennsylvania 19104 and ${ }^{2}$ Perelman School of Medicine, University of Pennsylvania, Philadelphia, Pennsylvania 19104

\begin{abstract}
Exposure to stress increases the risk of developing affective disorders such as depression and post-traumatic stress disorder (PTSD). However, these disorders occur in only a subset of individuals, those that are more vulnerable to the effects of stress, whereas others remain resilient. The coping style adopted to deal with the stressor, either passive or active coping, is related to vulnerability or resilience, respectively. Important neural substrates that mediate responses to a stressor are the orexins. These neuropeptides are altered in the cerebrospinal fluid of patients with stress-related illnesses such as depression and PTSD. The present experiments used a rodent social defeat model that generates actively coping rats and passively coping rats, which we have previously shown exhibit resilient and vulnerable profiles, respectively, to examine if orexins play a role in these stress-induced phenotypes. In situ radiolabeling and qPCR revealed that actively coping rats expressed significantly lower prepro-orexin mRNA compared with passively coping rats. This led to the hypothesis that lower levels of orexins contribute to resilience to repeated social stress. To test this hypothesis, rats first underwent 5 $\mathrm{d}$ of social defeat to establish active and passive coping phenotypes. Then, orexin neurons were inhibited before each social defeat for three additional days using designer receptors exclusively activated by designer drugs (DREADDs). Inhibition of orexins increased social interaction behavior and decreased depressive-like behavior in the vulnerable population of rats. Indeed, these data suggest that lowering orexins promoted resilience to social defeat and may be an important target for treatment of stress-related disorders.
\end{abstract}

Key words: Anxiety and depression; DREADDs; hypocretin; resilience; social defeat; vulnerability

\section{Significance Statement}

Stress-related mental illnesses occur in only a subset of individuals, whereas others are resilient to the effects of stress. Our work used an animal model of social stress to identify a substrate of resilience, the neuropeptides orexins, which are known to be altered in patients with major depressive disorder and PTSD. We found that orexins are decreased in rats resilient to social stress. To test whether low orexins contribute to resilience, orexins were inhibited during $3 \mathrm{~d}$ of a social defeat stress paradigm, which increased subsequent social interaction behavior and decreased depressive-like behaviors in a previously vulnerable population of rats. This suggests that lowering orexins is important in promoting resilience to stress and that orexins are an important target for treatments of stress-related illness.

\section{Introduction}

Exposure to chronic stress is associated with the onset and increased incidence of stress-related mental illness

Received August 3, 2017; accepted February 5, 2018; First published March 29, 2018.

The authors declare no competing financial interests. such as depression, anxiety-related disorders, and posttraumatic stress disorder (PTSD) (McEwen and Stellar, 1993; Yehuda et al., 1994; Ehlert et al., 2001). However, 
these disorders occur in only a subset of individuals that are more vulnerable to the effects of stress, whereas others remain resilient to the effects of stress. The neurobiological basis for these vulnerable and resilient phenotypes is not fully understood. Determining the neural substrates underlying vulnerability or resilience could lead to individualized treatment to either prevent vulnerability or promote resilience to stress.

Many stress-related disorders are associated with alterations in arousal. For example, PTSD is characterized by hypervigilance and hyperarousal to stimuli related to the traumatic event (Yehuda, 2000). Important neural substrates that mediate arousal, wakefulness, and vigilance are the neuropeptides orexins (de Lecea et al., 1998; Sakurai et al., 1998). Extending beyond their role in mediating general arousal and wakefulness, orexins are important in the response to stressful stimuli that require the animal to shift from a basal to a reactive state (Berridge and España, 2005). More specifically, orexins are known to promote the stress response including activation of both the sympathetic nervous system and the hypothalamic-pituitary-adrenal axis (Jászberényi et al., 2000; Kuru et al., 2000; Winsky-Sommerer et al., 2005; Spinazzi et al., 2006; Heydendael et al., 2011; Kuwaki, 2011; Johnson et al., 2012; Messina et al., 2014). Conversely, orexin neurons are activated by stressors such as forced swim and can also be activated by direct administration of the stress regulatory peptide corticotropin-releasing hormone (Winsky-Sommerer et al., 2005; Chang et al., 2007; Furlong et al., 2009; Chen et al., 2013). Importantly, orexin levels are altered in the CSF of patients with depression and PTSD. Together, both preclinical and clinical data suggest that orexins are involved in the processes by which stress leads to some psychiatric disorders (Strawn et al., 2010; Johnson et al., 2012). However, it is not known whether orexins contribute to individual differences that occur in response to stress, which are important in determining an individual's resilience or vulnerability to some psychiatric disorders.

One factor relating to susceptibility and resiliency is the coping style adopted to deal with the stressor (Veenema et al., 2003). Both active coping, characterized by the fight or flight response, and passive coping, characterized by heightened immobility, could be engaged during exposure to threatening stimuli (i.e., stressors; Engel and Schmale, 1972; Koolhaas et al., 1999; Southwick et al., 2005; Wood and Bhatnagar, 2015). Clinical studies have

This work was supported by National Institutes of Mental Health (NIMH) grant number R21MH102735 to S.B. L.A.G. was supported by award number F32MH109269 from NIMH. The content is the sole responsibility of the authors and does not necessarily represent the official views of the NIMH.

Acknowledgments: We gratefully acknowledge the dedicated assistance of Sandra Luz and Elizabeth Feindt-Scott.

Correspondence should be addressed to Seema Bhatnagar, Abramson Research Center, Suite 402B, Children's Hospital of Philadelphia, 3615 Civic Center Blvd, Philadelphia, PA 19104. E-mail: bhatnagars@email.chop.edu.

DOI:http://dx.doi.org/10.1523/ENEURO.0273-17.2018

Copyright @ 2018 Grafe et al.

This is an open-access article distributed under the terms of the Creative Commons Attribution 4.0 International license, which permits unrestricted use, distribution and reproduction in any medium provided that the original work is properly attributed. indicated that humans demonstrating passive coping are more likely to develop depression than those who display active coping (Folkman and Lazarus, 1980; Billings and Moos, 1984). The present experiments used an animal model of social stress in which coping strategies vary and are associated with resilience or vulnerability to stress, as assessed by measures in the neuroendocrine system, behavior (Wood et al., 2010, 2015; Chen et al., 2015b; Finnell et al., 2017b), and inflammatory processes (PearsonLeary et al., 2017).

These experiments aimed to examine orexins as a potential substrate underlying differences in vulnerability and resilience in response to social defeat stress in rats. First, orexin expression was measured by in situ radiolabeling and by quantitative PCR (qPCR) in passive coping (vulnerable) and active coping (resilient) rats, revealing that orexin expression was lower in resilient rats. This led to the hypothesis that lower levels of orexin underlie resilience to repeated social stress. To test this hypothesis, after rats had established active or passive coping phenotypes over $5 \mathrm{~d}$ of social defeat, orexin neurons were inhibited before each social defeat for three additional days using designer receptors exclusively activated by designer drugs (DREADDs). Dampening orexin action in passively coping rats before each defeat increased social interaction and decreased depressive-like behavior, promoting resilience. These studies establish that low orexin function contributes to the active/resilient behavioral phenotypes in response to repeated social defeat stress.

\section{Materials and Methods}

\section{Animals}

Adult, male Sprague-Dawley rats (275-300 g at time of stress) were used as controls or intruders (Charles River), and male Long-Evans retired breeders (650-850 g) served as residents (Charles River). Rats were individually housed with a 12-h light, 12-h dark cycle (lights on at 0700) in a climate-controlled room with ad libitum food and water. Rats were given $5 \mathrm{~d}$ of acclimation before experimentation. Studies were approved by Children's Hospital of Philadelphia Research Institute's Institutional Animal Care and Use Committee and conformed to the National Institutes of Health Guide for the Use of Laboratory Animals.

\section{Social defeat paradigm}

The social defeat paradigm used in this study was based on the resident-intruder model originally developed by Miczek (1979) (see Fig. 1A). Sprague-Dawley rats were randomly assigned to either a control or social defeat group. During social defeat, each rat was placed into the home cage of an unfamiliar Long-Evans retired breeder (resident) for each of 5-8 consecutive days. Typically, the resident and intruder investigate each other for a short period of time (1-3 min), followed by attacks by the resident, which result in a defeat of the intruder. A defeat was determined when the intruder assumed a supine posture and froze for at least 2-3 s. On assuming the defeat posture, the resident and intruder were separated by a wire mesh barrier until $30 \mathrm{~min}$ had elapsed from time of 


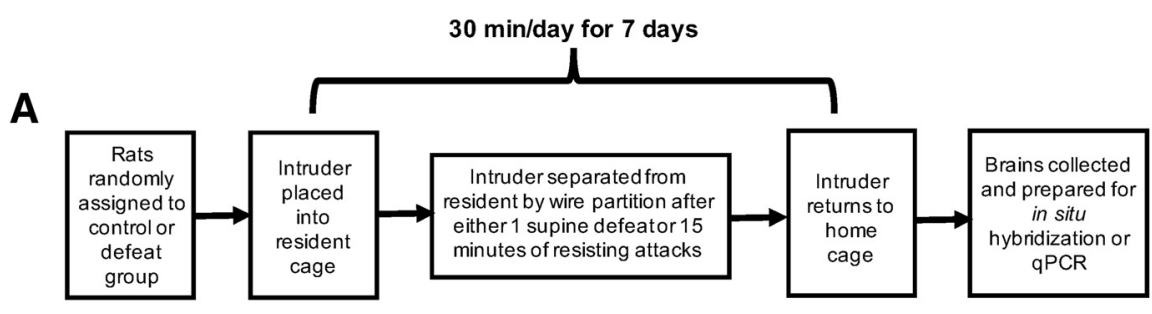

C
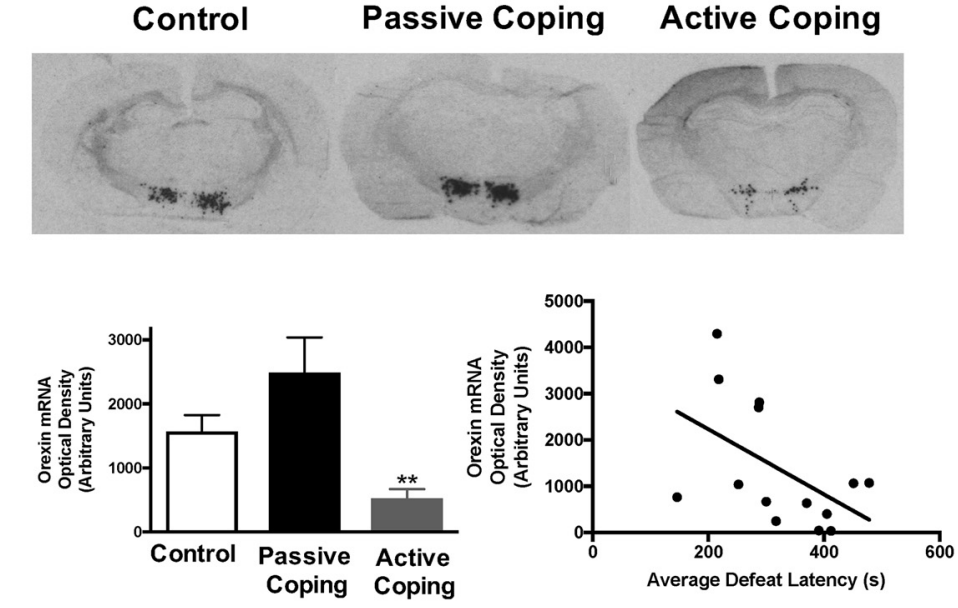

B

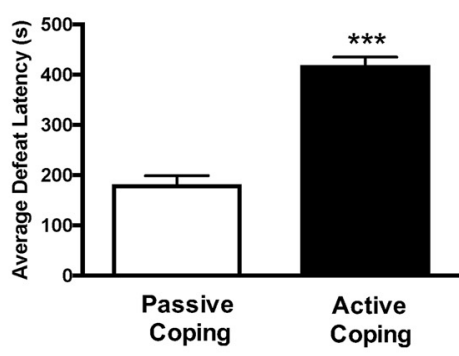

D
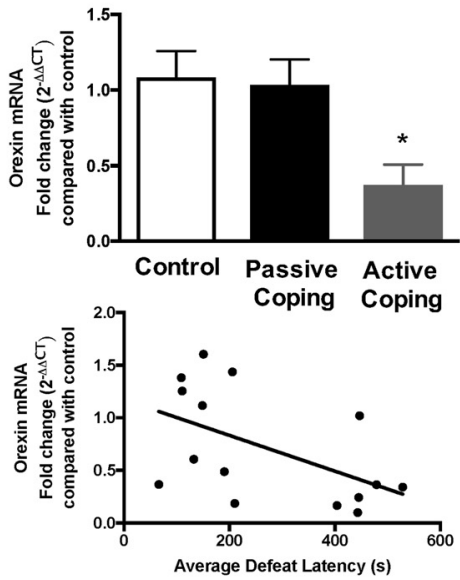

Figure 1. Social defeat paradigm and prepro-orexin expression in control and defeated rats. $\boldsymbol{A}$, Social defeat paradigm. $\boldsymbol{B}$, Average defeat latency over $7 \mathrm{~d}$ of social defeat. Passively coping rats have an average defeat latency $<300 \mathrm{~s}$, whereas actively coping rats have an average defeat latency $>300 \mathrm{~s}$. C. Prepro-orexin expression in control, passive coping, and active coping rats. Top: representative images of in situ radiolabeling for prepro-orexin in control, passive coping, and active coping rats. Bottom: quantification of in situ radiolabeling in each treatment group reveals that actively coping rats have significantly less prepro-orexin mRNA in the lateral hypothalamus compared with control or passively coping rats. There is a negative correlation between average defeat latency and in situ radiolabeled orexin mRNA. $\boldsymbol{D}$, Prepro-orexin mRNA expression in control, passive coping, and active coping rats as measured by qPCR. Actively coping rats express significantly less prepro-orexin mRNA than control and passively coping rats. There is a negative correlation between average defeat latency and qPCR-quantified orexin mRNA. $*, p<0.05 ; * *, p<0.01$; $* * *, p<0.001$.

initial placement into the cage of the resident. The barrier allowed for visual, auditory, and olfactory contact but prevented physical contact and further attacks on the intruder. The latency to be defeated was then recorded. If no defeat occurred within $15 \mathrm{~min}$, the rats were separated with a wire mesh barrier for the remaining $15 \mathrm{~min}$. Control rats were placed into a clean novel cage behind a wire mesh barrier for $30 \mathrm{~min}$. Once the 30 -min social stress was complete, each rat was placed back in its home cage. The average latency of each rat over the course of $7 \mathrm{~d}$ was entered into an R script used to perform cluster analyses on average defeat latencies (code available at www.github.com/cookpa/socialdefeat). The bootstrap classification starts from the assumption that the average latencies are drawn from a bimodal distribution. An initial classification of the average latencies is performed using "partitioning around medoids" (PAM) implemented in R's cluster package (Reynolds et al., 1992). PAM is a robust implementation of $k$-means clustering, which separates data into a predefined number of clusters (in this case, 2 , one for passive coping and one for active coping). The bootstrap algorithm resamples the data to assess the uncertainty in the classification. For each bootstrap itera- tion, we sample with replacement from the original latencies and rerun the PAM clustering. After 10,000 iterations, we define the probability of active coping classification for each of the average latencies as the fraction of the 10,000 bootstrap iterations in which that latency is classified as active coping. Latencies that are consistently classified as active coping have probability 1.0 , and those classified consistently as passive coping have probability 0.0 . Rats with a value between 0.1 and 0.9 changed their classification in $>10 \%$ of the bootstrap samples, and these animals were excluded from the experiment. Four animals of 42 were excluded based on this criterion.

\section{Experiment 1: Social defeat and prepro-orexin expression}

In one cohort of either control rats or those exposed to 7-d social defeat, in situ hybridization was used to measure the level of prepro-orexin mRNA in the lateral hypothalamus. Briefly, $20-\mu \mathrm{m}$ sections of the lateral hypothalamus from brains of control, passively coping, and actively coping rats were collected on a cryostat (rostralcaudal coordinates relative to bregma: -1.30 to -4.60 $\mathrm{mm}$ ) and processed for in situ hybridization. Hybridization 
localization of mRNAs using ${ }^{35} \mathrm{~S}$-labeled antisense mRNA probes was performed. In short, coronal brain slices encompassing the lateral hypothalamus were hybridized, in situ, with antisense to orexin (donated by Dr. Teresa Reyes, University of Cincinnati). Hybridizations for all slices were conducted in a single lot followed by analysis of the signal on x-ray film. Routine controls consisted of sense-strand probes labeled to similar specific activities as the antisense probes. X-ray films were analyzed using ImageJ. Background estimates were produced by optical density measurements over non-positively hybridized regions.

Another cohort of either control rats or those exposed to $7 \mathrm{~d}$ of social defeat was used to assess orexin mRNA by qPCR. Control, passively coping, and actively coping rats were killed and fresh punches of lateral hypothalamus were collected. RNA was extracted with Purelink mRNA kit according to the manufacturer's protocol (Thermo Fisher Scientific). RNA was reverse transcribed to cDNA using a high-capacity cDNA reverse transcription kit (Thermo Fisher Scientific). qPCR was performed using Taqman Gene Expression Assays (Thermo Fisher Scientific) with primers for prepro-orexin (Hs01891339_s1) and Actb (Hs01060665_g1) and the Applied Biosystems 7500 Real Time PCR System.

\section{Experiment 2: Inhibiting orexins during social defeat using DREADDs}

DREADDs are viruses that contain synthetic GPCRs and can be activated by the otherwise pharmacologically inert ligand clozapine- $N$-oxide (CNO). We obtained the CMV-hM4Di-mCitrine plasmid from Dr. Bryan Roth (University of North Carolina, Chapel Hill). Slice electrophysiology has demonstrated that CNO application to hippocampal cells expressing this Gi-coupled designer receptor causes hyperpolarization and decreased firing rate (Armbruster et al., 2007). Recent studies have found that $\mathrm{CNO}$ silencing of particular brain areas can produce striking behavioral effects, such as a reduction in anxietylike behavior (McCall et al., 2015). We next obtained a 1295-bp promoter for human prepro-orexin gene (Ple112) from Addgene plasmid no. 29004 (gift of Dr. Elizabeth Simpson, University of British Columbia). This promoter was subcloned upstream of the hM4Di-mCitrine region to replace the construct's CMV promoter to drive transgene expression specifically in orexin neurons. The fragment Ple112-hm4Di-mCitrine was then subcloned between the inverted terminal repeats (ITRs) of the AAV2 genome. In a separate study, we found that AAV1 serotype displayed optimal tropism for Sprague-Dawley rat hypothalamic neurons when delivered in vivo and compared to AAV5, 8, and 9 expression of GFP reporters driven by common constitutively active promoters Synapsin and CB7. Based on this finding, the University of Pennsylvania Viral Vector Core produced a recombinant adenovirus rAAV2/1-Ple112-hM4Di-mCitrine (using AAV1 serotype capsid for optimal transduction in orexin neurons) for our use. Previous studies using this virus demonstrate that activation of this construct in vivo decreases cFos expression in orexin neurons, supporting the efficacy of this construct (Grafe et al., 2017a).
Five cohorts of male rats (20 rats per cohort) were anesthetized using a cocktail of ketamine, xylazine, and acepromazine. Using stereotaxic technique, virus containing the DREADDs construct $\left(10^{9}\right.$ titer, $1 \mu$ l bilaterally) was injected into the lateral hypothalamus $(2.5 \mathrm{~mm}$ caudal to bregma, $1.8 \mathrm{~mm}$ from midline and $8 \mathrm{~mm}$ ventral). We verified the expression of the DREADDs constructs by immunofluorescence and determined that optimal expression occurs at $4 \mathrm{wk}$ postinjection. Thus, virus was expressed for $4 \mathrm{wk}$ before social defeat procedures, and subsequent behavior was assessed (see experimental paradigm in Fig. 2A).

Male rats expressing DREADDs-containing virus were either assigned to a control condition or exposed to the social defeat paradigm. Defeated rats were exposed to 5 $\mathrm{d}$ of social defeat without orexin manipulation, allowing the emergence of passively and actively coping phenotypes based on average defeat latency over those $5 \mathrm{~d}$. In the original study describing these naturally occurring differences in response to social defeat (Wood et al., 2010), the 5-d latencies are predictive of the 7-d defeat latencies. In addition, previous publications have demonstrated that $5 \mathrm{~d}$ of social defeat is sufficient to induce depressive-like behavior in passively coping rats (but not actively coping rats; Wood et al., 2015; Finnell et al., 2017a). Thus, $5 \mathrm{~d}$ of defeat is comparable to the $7 \mathrm{~d}$ of defeat as performed in experiment 1 . Body weights were collected both before and after the $5 \mathrm{~d}$ of defeat. Then control, actively coping, and passively coping rats were randomly assigned to a vehicle or $\mathrm{CNO}$ group. In these rats, on days $6-8$, either vehicle (saline and $8 \%$ dimethyl sulfoxide) or CNO (2 mg/kg; Sigma-Aldrich) was injected $60 \mathrm{~min}$ before each defeat (or at the same time of day in control rats). This dose is in accordance with doses used in previous DREADDs studies in rats (Farrell and Roth, 2013) and those we have previously used to inhibit orexin neurons using hM4Di DREADDs. This timing was chosen because CNO promotes behavioral effects in the rat within 30 min of administration, and effects last up to $4 \mathrm{~h}$ after administration (Alexander et al., 2009; Farrell and Roth, 2013; Hasegawa et al., 2014). Thus, the final groups were vehicle-treated control rats, $\mathrm{CNO}$-treated control rats, vehicle-treated passively coping rats, $\mathrm{CNO}$-treated passively coping rats, vehicle-treated actively coping rats, and CNO-treated actively coping rats.

On day 9, two cohorts were sacrificed, and in situ hybridization was used to measure the level of preproorexin mRNA in the lateral hypothalamus, as described in experiment 1. Three other cohorts were exposed to a social interaction test in a $70 \times 70-\mathrm{cm}$ arena. In brief, rats were placed in the arena with another male SpragueDawley rat of similar size and weight. Rats were allowed to interact in this arena for $15 \mathrm{~min}$ and were videotaped and analyzed by Ethovision XT video tracking software (Noldus Information Technology). Latency to interact (time in seconds until experimental rat explores stimulus rat), total time interacting (number of seconds that the experimental rat explores stimulus rat), and distance moved were calculated. Total time interacting and latency to 

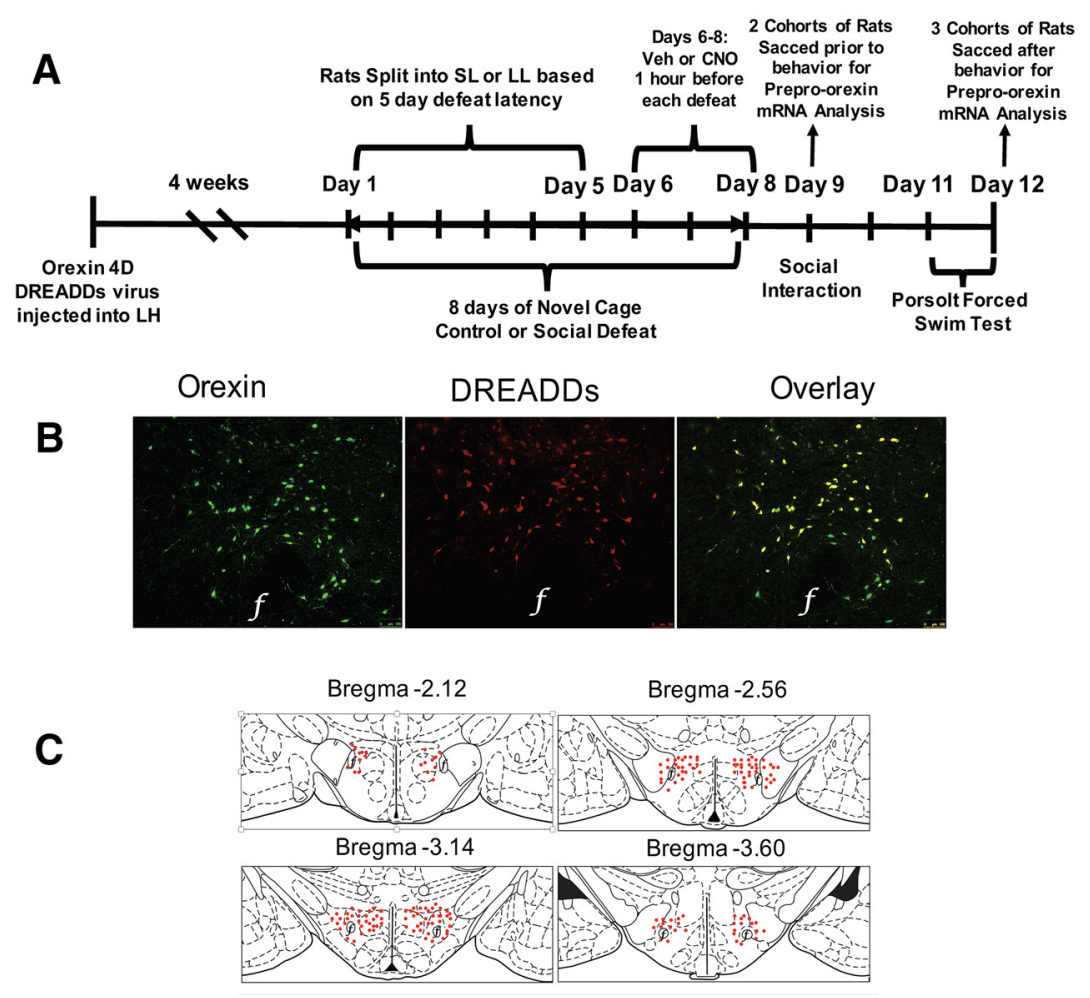

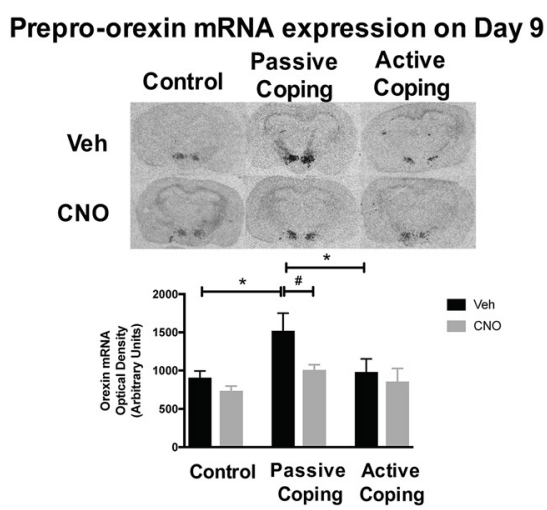

E Prepro-orexin mRNA expression on Day 12

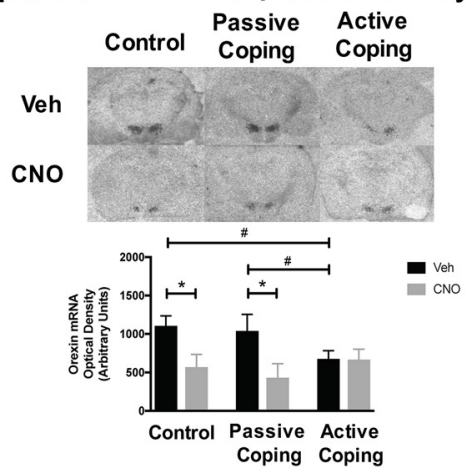

Figure 2. Expression of DREADDs-containing virus and inhibiting orexins during social defeat. $\boldsymbol{A}$, A timeline of the experimental paradigm. 4 wk after DREADDs injection, rats are exposed to $8 \mathrm{~d}$ of social defeat (the latter $3 \mathrm{~d}$ Veh or CNO is injected before defeat), followed by social interaction and forced swim test. $\boldsymbol{B}$, Representative images displaying viral expression of DREADDs in the lateral hypothalamus (LH) at 4 wk. C, Composite image displaying the spread of viral expression along the LH is depicted using rat brain atlas images (Paxinos and Watson, 1998). Each red dot represents a cell expressing the viral tag. $\boldsymbol{D}$, Prepro-orexin expression in vehicleand CNO-treated control, passive coping, and active coping rats on day 9 (before further behavioral testing). Top: representative images of in situ radiolabeling for vehicle- and CNO-treated prepro-orexin in control, passive coping, and active coping rats. Bottom: quantification of in situ radiolabeling in each treatment group reveals that actively coping rats have significantly less prepro-orexin mRNA in the lateral hypothalamus compared with passively coping rats. CNO treatment reduces prepro-orexin expression in passively coping rats to levels similar to that of actively coping rats. $\boldsymbol{E}$, Prepro-orexin expression in vehicle- and CNO-treated control, passive coping, and active coping rats on day 12 (after social interaction and forced swim test behaviors). Top: Representative images of in situ radiolabeling for vehicle- and CNO-treated prepro-orexin in control, passive coping, and active coping rats. Bottom: quantification of in situ radiolabeling in each treatment group reveals that actively coping rats have less prepro-orexin mRNA in the lateral hypothalamus compared with passively coping rats. CNO treatment reduces prepro-orexin expression in both control and passively coping rats to levels similar to that of actively coping rats. $*, p<0.05$;,$p<0.10$.

interact were verified by hand coding from an observer blind to experimental conditions.

On days 11 and 12, rats were tested in the Porsolt forced swim test (FST). Based on the work of Lucki (1997), FST was performed on two consecutive days. Rats were exposed to $15 \mathrm{~min}$ of forced swim (day 1), followed $24 \mathrm{~h}$ later by a 5-min forced swim (day 2). The 5-min swim test was videotaped from directly above the clear glass cylinder (46 cm height, $20 \mathrm{~cm}$ diameter), filled to $35 \mathrm{~cm}$ with water at a temperature of $25^{\circ} \mathrm{C}\left( \pm 1^{\circ} \mathrm{C}\right)$. Two trained observers categorized the rat's videotaped behavior (day 2) every $5 \mathrm{~s}$ for immobility, swimming, or climbing. Percentage time swimming and climbing were also combined to analyze percentage time active.

After all behavioral experiments were complete, animals were killed, brains were collected, and $20-\mu \mathrm{m}$ lateral hypothalamic slices were analyzed for both prepro-orexin mRNA expression (as previously described) and viral ex- pression. Specifically, immunofluorescence for visualizing the virus tag was conducted as follows. Tissue was incubated with primary antibodies for both Orexin A (1:250, sc-8070; Santa Cruz Biotechnology) and GFP (1:500, ab290; Abcam). As the mCitrine tag on the DREADDS virus originates from Aequorea victoria jellyfish, GFP antibodies are known to react with these proteins (Le et al., 2006). Sections were then incubated with Alexa Fluor 488 donkey anti-goat and Alexa Fluor 647 donkey anti-rabbit secondary antibodies (1:200, A-11055 and A-31573; Life Technologies). Images were acquired with a Leitz DMR microscope with a digital camera (Leica; Fig. 2B). The NIH ImageJ colocalization plugin was used to determine percentage orexin cells transduced by the virus. Approximately $70 \%$ of the orexin cells are transfected at this time, consistent with previous studies. The numbers of DREADDs-expressing cells and Orexin A-labeled cells were also methodically counted from anterior to posterior 
Table 1. Statistical analysis

\begin{tabular}{|c|c|c|c|}
\hline Location & Data structure & Type of test & Confidence interval (95\%) \\
\hline a & Normal distribution & $t$ test & Passive vs. active latency: 189.8 to 284.3 \\
\hline b & Normal distribution & $\begin{array}{l}\text { One-way ANOVA, Tukey's } \\
t \text { test }\end{array}$ & $\begin{array}{l}\text { Control vs. active coping orexin mRNA: } 1.3 \text { to } 2093 \text {; passive vs. } \\
\text { active coping orexin mRNA: } 749.8 \text { to } 3180\end{array}$ \\
\hline C & Normal distribution & Correlation & Latency vs. orexin mRNA: -0.8 to 0.0 \\
\hline d & Normal distribution & $\begin{array}{l}\text { One-way ANOVA, Tukey's } \\
t \text { test }\end{array}$ & $\begin{array}{l}\text { Control vs. active coping orexin mRNA: } 0.2 \text { to } 1.2 \text {; passive vs. } \\
\text { active coping orexin mRNA: } 0.1 \text { to } 1.2\end{array}$ \\
\hline e & Normal distribution & Correlation & Latency vs. orexin mRNA: -0.8 to -0.0 \\
\hline f & Normal distribution & $\begin{array}{l}\text { One-way ANOVA, Tukey's } \\
t \text { test }\end{array}$ & $\begin{array}{l}\text { Control vs. passive coping body weight: } 5.6 \text { to } 19.5 \text {; control vs. } \\
\text { active coping body weight: } 0.2 \text { to } 13.8\end{array}$ \\
\hline g & Normal distribution & $\begin{array}{l}\text { Two-way ANOVA, Tukey's } \\
t \text { test }\end{array}$ & $\begin{array}{l}\text { Vehicle-treated control vs. vehicle-treated passive coping orexin } \\
\text { mRNA: }-1157 \text { to }-73.81 \text {; vehicle-treated passive coping vs. } \\
\text { vehicle-treated active coping orexin mRNA: } 80.6 \text { to } 1002 ; \\
\text { vehicle-treated passive coping vs. CNO-treated passive } \\
\text { coping orexin mRNA: }-26.99 \text { to } 1057\end{array}$ \\
\hline h & Normal distribution & $\begin{array}{l}\text { Two-way ANOVA, Tukey's } \\
t \text { test }\end{array}$ & $\begin{array}{l}\text { Vehicle-treated passive coping vs. vehicle-treated active coping } \\
\text { interaction time: }-101.5 \text { to }-0.6 \text {; vehicle-treated passive } \\
\text { coping vs. CNO-treated passive coping interaction time: } \\
-116.6 \text { to }-8.6\end{array}$ \\
\hline i & Normal distribution & $\begin{array}{l}\text { Two-way ANOVA, Tukey's } \\
t \text { test }\end{array}$ & $\begin{array}{l}\text { Vehicle-treated control vs. vehicle-treated passive coping } \% \\
\text { immobility: }-26.4 \text { to }-3.9 \text {; vehicle-treated control vs. CNO- } \\
\text { treated control } \% \text { immobility: }-25.7 \text { to }-5.6 \text {; vehicle-treated } \\
\text { passive coping vs. CNO-treated passive coping \% immobility: } \\
0.6 \text { to } 23.7\end{array}$ \\
\hline j & Normal distribution & $\begin{array}{l}\text { Two-way ANOVA, Tukey's } \\
t \text { test }\end{array}$ & $\begin{array}{l}\text { Vehicle-treated control vs. vehicle-treated passive coping } \% \\
\text { activity: } 3.9 \text { to } 26.4 \text {; vehicle-treated control vs. CNO-treated } \\
\text { control } \% \text { activity: } 5.6 \text { to } 25.6 \text {; vehicle-treated passive coping } \\
\text { vs. CNO-treated passive coping } \% \text { activity: }-23.7 \text { to }-0.6\end{array}$ \\
\hline k & Normal distribution & $\begin{array}{l}\text { Two-way ANOVA, Tukey's } \\
t \text { test }\end{array}$ & $\begin{array}{l}\text { Vehicle-treated control vs. vehicle-treated passive coping \% } \\
\text { swimming: } 4.3 \text { to } 26.3 \text {; vehicle-treated control vs. CNO- } \\
\text { treated control \% swimming: } 3.5 \text { to } 24.0\end{array}$ \\
\hline l & Normal distribution & $t$ test & Vehicle vs. CNO-treated social interaction time: -32.5 to 50.8 \\
\hline m & Normal distribution & $t$ test & Vehicle vs. CNO-treated social interaction latency: -24.8 to 38.8 \\
\hline $\mathrm{n}$ & Normal distribution & $t$ test & $\begin{array}{l}\text { Vehicle vs. CNO-treated social interaction distance traveled: } \\
-38,305 \text { to } 63,114\end{array}$ \\
\hline o & Normal distribution & $t$ test & Vehicle vs. CNO-treated \% immobility: -5.7 to 21.8 \\
\hline $\mathrm{p}$ & Normal distribution & $t$ test & Vehicle vs. CNO-treated \% activity: -21.8 to 5.7 \\
\hline q & Normal distribution & $\begin{array}{l}\text { Two-way ANOVA, Tukey's } \\
t \text { test }\end{array}$ & $\begin{array}{l}\text { Vehicle-treated control vs. vehicle-treated active coping orexin } \\
\text { mRNA: }-35.82 \text { to } 889.3 \text {; vehicle-treated passive coping vs. } \\
\text { vehicle-treated active coping orexin mRNA: }-121.5 \text { to } 846.1 \text {; } \\
\text { vehicle-treated control vs. CNO-treated control orexin mRNA: } \\
92.88 \text { to } 975.8 \text {; vehicle-treated passive coping vs. CNO- } \\
\text { treated passive coping orexin mRNA: } 123.8 \text { to } 1091\end{array}$ \\
\hline
\end{tabular}

extent of the lateral hypothalamus $(-2.12$ to $-3.60 \mathrm{~mm}$; Fig. 2C).

\section{Statistical analysis}

Data are presented as the mean \pm SEM. For orexin expression by in situ and QPCR, and body weight gain, one-way ANOVA was performed, followed by Tukey's post hoc $t$ test. For orexin expression (before and after behavior), social interaction, and forced swim test data, two-way ANOVA [stress (control, passive coping, or active coping) by drug (vehicle or $\mathrm{CNO}$ ) treatments] was used, followed by Tukey's post hoc $t$ tests. All analyses used $\alpha=0.05$ as the criterion level of significance. Statistical analysis was conducted with GraphPad Prism (GraphPad Software) to identify statistical differences. Superscript letters listed with $p$-values correspond to the statistical tests shown in Table 1.

\section{Results}

\section{Prepro-orexin expression in rats vulnerable or resilient to defeat}

After $7 \mathrm{~d}$ of social defeat (Fig. 1A), rats were split into passive coping and active coping clusters based on average latency to defeat. Rats that displayed passive coping had an average defeat latency of $182 \mathrm{~s}$, whereas rats that displayed active coping had an average defeat latency of $419 \mathrm{~s}$ (Fig. 1B; $p<0.001^{\mathrm{a}}$, $t$ test, $n=16 /$ group). Prepro-orexin expression was then examined in two separate cohorts of control, passively coping, and actively coping rats; one cohort was used for in situ radiolabeling and the other was used for GPCR. Quantification of in situ radiolabeling in each treatment group revealed that actively coping rats had significantly less prepro-orexin mRNA in the lateral hypothalamus compared with passively coping rats (Fig. $1 C, F(2,23)=8.4, p=0.002^{\text {b }}$; 
A

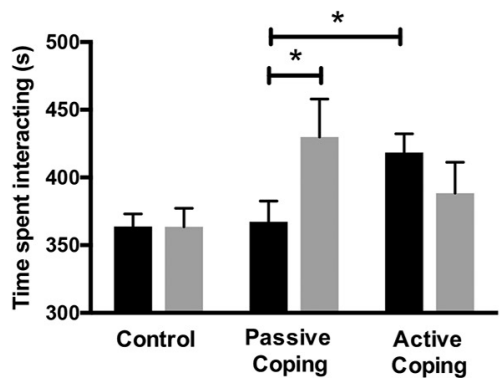

B

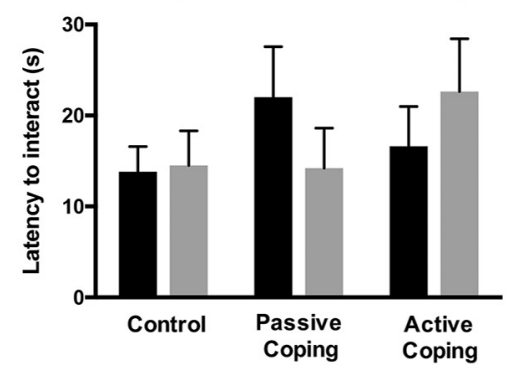

C

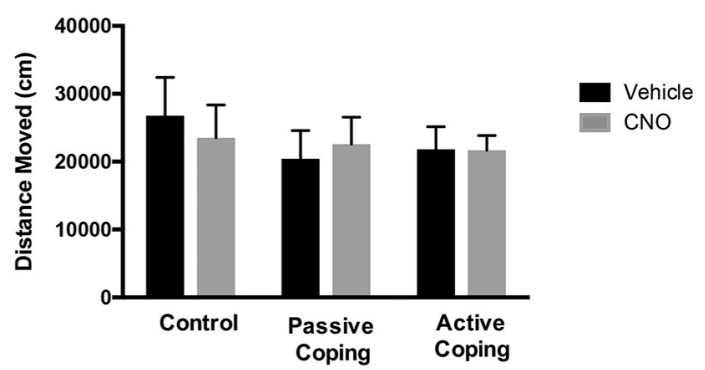

Figure 3. Social interaction behavior after the social defeat paradigm. A, Time spent interacting with the stimulus rat. Actively coping rats spend significantly more time interacting than passively coping rats. CNO treatment (inhibition of orexin neurons) increases time spent interacting in passively coping rats. $\boldsymbol{B}$, Latency to interact with the stimulus rat. There were no significant differences in latency to interact between the treatment groups. $\boldsymbol{C}$, Distance moved in the social interaction arena. There were no significant differences in the distance moved between the treatment groups. $*, p<0.05$.

one-way ANOVA followed by Tukey's $t$ test; $n=8 /$ group, 4 slices per animal). Moreover, there was a trend for a negative correlation between average defeat latency and prepro-orexin $\mathrm{mRNA}$ as measured by in situ radiolabeling (Fig. $1 C, R^{2}=0.260, p=0.062^{\circ}$ ). qPCR analysis of prepro-orexin levels in another cohort of rats demonstrated a consistent result: rats that displayed active coping expressed significantly less prepro-orexin mRNA than passively coping rats (Fig. $1 D, F\left(2,22=4.4, p=0.025^{\mathrm{d}}\right.$, one-way ANOVA followed by Tukey's $t$ test; $n=8$ /group). Average defeat latency was negatively correlated with orexin mRNA as quantified by qPCR $\left(R^{2}=0.276, p=\right.$ $\left.0.044^{\mathrm{e}}\right)$. Together, these results demonstrate that lower orexin expression is associated with an active coping strategy, and thus, based on previous findings (Wood et al., 2010), a resilient phenotype.

\section{Inhibition of orexins during the last $\mathbf{3} \mathrm{d}$ of social defeat using DREADDs}

To determine the effects of orexin inhibition on behavioral outcomes produced by social defeat, rats were first injected with an inhibitory DREADDs viral construct which was allowed to express for 4 wk (for experimental paradigm and confirmation of DREADDs expression, see Fig. $2 A-C)$. Next, rats underwent social defeat for $5 d$ and were split into passive and active coping groups based on average defeat latency (see Methods for more detail on how this analysis was performed). As expected, body weight gain was significantly different between control and defeated groups (data not shown; $F(2,38)=6.766$, $p=0.003^{f}$, one-way ANOVA followed by Tukey's $t$ test; $n=16$ /group). Specifically, control rats that did not undergo social defeat stress showed significantly more weight gain than those that did. In addition, rats that displayed passive coping had less weight gain compared with actively coping rats.

Two cohorts of rats were sacrificed before social interaction behavior to examine the effect of social defeat and vehicle or CNO treatment on prepro-orexin mRNA expression (Fig. 2D). Prepro-orexin mRNA levels appeared to differ between treatment groups (defeat effect, $F(2,27)=$ $3.2, p=0.055^{9}$; CNO effect, $F(1,27)=3.6, p=0.067$, two-way ANOVA, followed by $t$ tests, $n=6 /$ group). Par- ticularly, vehicle-treated actively coping rats had lower levels of prepro-orexin mRNA than vehicle-treated passively coping rats. Thus, this phenotype of lower orexin expression in rats that demonstrate an active coping strategy is stable. Additionally, CNO treatment during the last $3 \mathrm{~d}$ of defeat reduced prepro-orexin mRNA levels in passive coping rats to that of control and active coping rats. To examine whether reducing orexins promotes behavioral correlates of resilience, 3 additional cohorts of rats were exposed to $5 \mathrm{~d}$ of social defeat followed by vehicle or CNO treatment before each defeat on days $6-8$. These cohorts were then assayed for anxiety-like behavior in the social interaction test and depressive-like behavior in the forced swim test.

On day 9 of the experimental paradigm, rats were tested for social interaction with a stimulus rat (Fig. 3). The amount of time spent interacting was significantly different between treatment groups (Fig. $3 A$; defeat effect, $F(2,48)=3.3, p=0.043^{\text {h }}$; interaction effect, $F(2,48)=3.4$, $p=0.045$, two-way ANOVA followed by Tukey's $t$ test, $n=12$ /group). Importantly, in vehicle-injected groups, actively coping rats spent significantly more time interacting than passively coping rats, replicating previous findings (Chen et al., 2015b; Pearson-Leary et al., 2017). CNO treatment (inhibition of orexin neurons during the last $3 \mathrm{~d}$ of social defeat) increased time spent interacting in passively coping rats but had no effect in actively coping rats or control rats. There were no significant differences in latency to interact between the treatment groups (Fig. 3B). Additionally, there were no significant differences in the distance moved between the treatment group, indicating that the manipulation of orexin action did not simply change general arousal or locomotor activity (Fig. 3C). Thus, dampening of orexin action during the last $3 \mathrm{~d}$ of social defeat specifically increased social interaction in the vulnerable population of rats to the level of resilient rats.

On days 11 and 12 of the experimental paradigm, rats were tested in the Porsolt forced swim paradigm to assess depressive-like behavior (Fig. 4). Analysis of percentage time immobile revealed significant differences between treatment groups (Fig. $4 A$; interaction effect, $F(2,47)=6.6, p=0.003^{i}$, two-way ANOVA followed by 
A

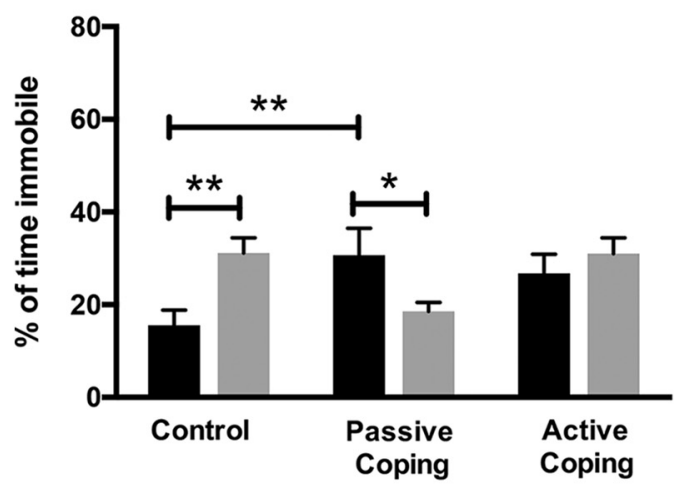

C

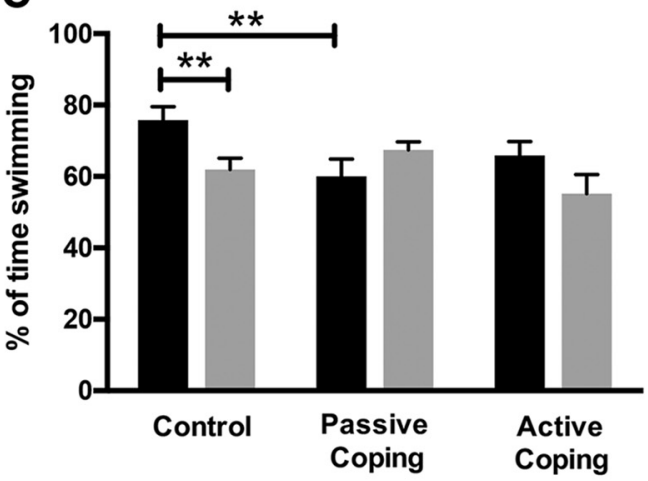

B

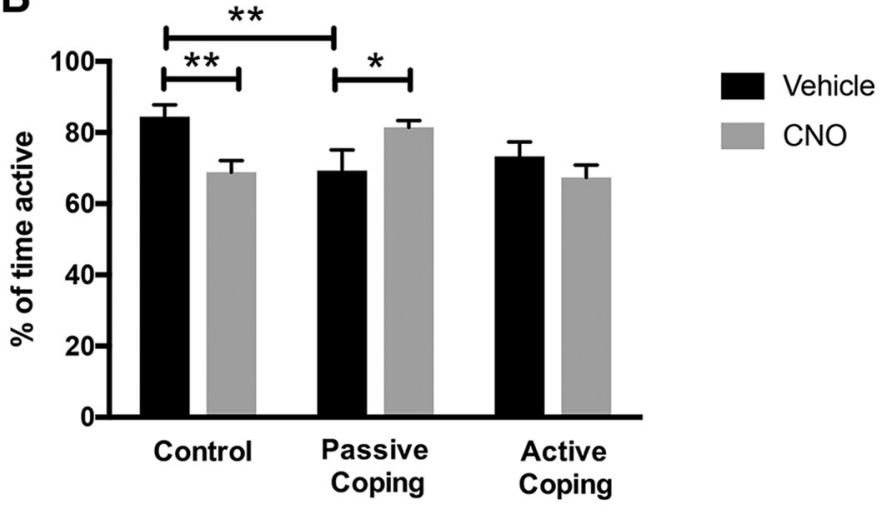

D

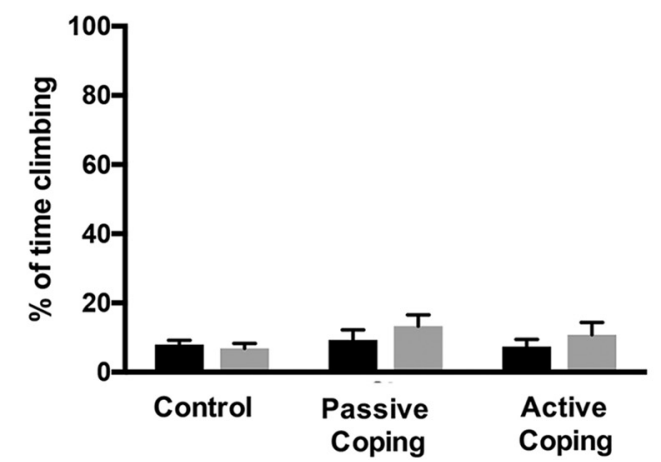

Figure 4. Forced swim test behavior after the social defeat paradigm. A, Percentage of time spent immobile in the forced swim test. Passively coping rats spend significantly more time immobile than control rats. CNO treatment (inhibition of orexin neurons) decreases time spent immobile in passively coping rats. CNO treatment (inhibition of orexin neurons) increases time spent immobile in control rats. $\boldsymbol{B}$, Percentage of time spent active in the forced swim test. Vehicle-treated passively coping rats spend significantly less time active than control rats. While CNO treatment decreases time spent active in control rats, it increases time spent active in passively coping rats. $\boldsymbol{C}$, Percentage of time spent swimming in the forced swim test. Passively coping rats spend significantly less time swimming than control rats. CNO treatment decreases time spent swimming in control rats. $\boldsymbol{D}$, Percentage of time spent climbing in the forced swim test. There were no significant differences in time spent climbing between the treatment groups. $*, p<0.05$; $* *, p<0.01$.

Tukey's $t$ test, $n=12 /$ group). Specifically, vehicle-treated passively coping rats spent significantly more time immobile than control rats, replicating previous findings (Wood et al., 2010). CNO treatment (inhibition of orexin neurons during the last $3 \mathrm{~d}$ of social defeat) decreased time spent immobile in passively coping rats but had no effect in actively coping rats. CNO treatment in control animals increased time spent immobile. Percentage time spent active was next analyzed, revealing that vehicle-injected passively coping rats spent less time active than control rats, and inhibition of orexin neurons during social defeat reversed this effect (Fig. $4 B$; interaction effect, $F(2,46)=$ $6.7, p=0.003^{\mathrm{j}}$, two-way ANOVA followed by Tukey's $t$ test, $n=12 /$ group). Activity was then subdivided into swimming and climbing behaviors. Analysis of swimming behavior revealed that vehicle-injected passively coping rats spent significantly less time swimming than vehicleinjected control rats (Fig. $4 C$; interaction effect, $F(2,46)=$ $4.1, p=0.022^{k}$, two-way ANOVA followed by Tukey's $t$ test, $n=12$ /group). Moreover, CNO treatment decreased time spent swimming in control rats but had no effect on passively or actively coping rats. Lastly, there were no significant differences between the treatment groups in climbing behavior (Fig. 4D). Thus, it appears that the differences in activity between treatment groups can mostly be attributed to swimming behavior. However, CNO treatment in passively coping rats appeared to increase a combination of both swimming and climbing; these measures were only significantly increased when summed together as total activity.

A control experiment was performed to determine if CNO alone had any impact on behavior in nonDREADDs-expressing rats. Specifically, a separate naive cohort of rats was injected with either vehicle or CNO for three consecutive days, followed by testing in the social interaction test and forced swim test. This was the same treatment regimen as in the original experiment above. The data indicate that total social interaction time did not differ between vehicle- and CNO-treated groups (395.6 \pm 10.5 vs. $404.8 \pm 16.5 \mathrm{~s}, p=0.600$ ', $t$ test, $n=6$ /group). Latency to interact was also not different between treatment groups $\left(13.0 \pm 2.9\right.$ vs. $19.4 \pm 6.0 \mathrm{~s}, p=0.534^{\mathrm{m}}, t$ test, $n=6$ /group). Moreover, distance traveled in the social interaction arena did not differ between treatment groups $(21,458.2 \pm 3872.1$ vs. $28,746.6 \pm 9193.6 \mathrm{~cm}, p=$ $0.403^{n}, t$ test, $n=6 /$ group). Lastly, neither percentage 
immobility nor total activity differed between vehicle- and CNO-treated groups in the forced swim test (immobility: $20.8 \pm 2.5$ vs. $28.9 \pm 4.2, p=0.19^{\circ}, t$ test, $n=6 /$ group; activity: $79.2 \pm 4.2$ vs. $71.1 \pm 2.5, p=0.19^{\mathrm{p}}, t$ test, $n=$ $6 /$ group). In summary, CNO treatment alone in nonDREADDs-expressing rats did not cause significant changes in the social interaction or forced swim test compared with vehicle-treated animals. These results indicate that the effects of DREADDs inhibition in the experiment above were not due to the effects of $\mathrm{CNO}$ alone.

Prepro-orexin mRNA levels differed between treatment groups after the forced swim test on day 12 (Fig. 2E, CNO effect, $F(1,38)=8.0, p=0.007^{q}$, two-way ANOVA followed by Tukey's $t$ test, $n=12$ /group). Namely, vehicletreated actively coping rats had lower prepro-orexin expression compared with vehicle-treated passively coping rats. Once again, this phenotype of lower orexin expression in actively coping rats is stable. CNO treatment reduced prepro-orexin expression in both control and passively coping rats. Overall, these results indicate that reducing orexin action in the last $3 \mathrm{~d}$ of social defeat increased social interaction time and reversed the depressive-like behavior observed in the vulnerable population of rats.

\section{Discussion}

These experiments used a social defeat paradigm that generates two different populations of rats that demonstrate either passive or active coping strategies, based on their average latency to be defeated. Previous studies have indicated that rats displaying a passive coping strategy demonstrate subsequent anxiety- and depressivelike behaviors (Wood et al., 2010; Chen et al., 2015b; Pearson-Leary et al., 2017). This is consistent with human studies, which have demonstrated that passive coping is more often associated with the development of major depressive disorder (MDD). Our results suggest a substrate of resilience, namely, the neuropeptides orexins, which are known to mediate the stress response and are altered in patients with MDD and PTSD (Kuru et al., 2000; Yehuda, 2000; Winsky-Sommerer et al., 2004; Spinazzi et al., 2006; Furlong et al., 2009; Strawn et al., 2010; Chen et al., 2015a). In short, we first discovered that lower orexin expression was associated with active coping strategies. We next inhibited orexin action during the last $3 \mathrm{~d}$ of social defeat, and this produced an increase in social interaction and a decrease in depressive-like behaviors in passively coping rats. Thus, we established that low orexin function contributes to the active/resilient behavioral phenotypes in response to repeated social defeat stress.

Both in situ radiolabeling and GPCR approaches revealed that rats displaying active coping (resilient rats) expressed significantly lower levels of prepro-orexin mRNA compared with rats that displaying passive coping (vulnerable rats) as well as control rats. This led to the hypothesis that it is the lower levels of orexins that underlie resilience to repeated social stress. To test this, rats first underwent $5 \mathrm{~d}$ of social defeat stress to establish active and passive coping phenotypes. Next, to deter- mine whether reducing orexins promotes resilience, we inhibited orexin neurons before each social defeat for three additional days using DREADDs. Importantly, we found that CNO treatment during the last $3 \mathrm{~d}$ of defeat reduced prepro-orexin mRNA levels in passive coping rats to that of active coping rats. Additionally, inhibition of orexin neurons before each defeat resulted in increased social interaction behavior and decreased immobility during forced swim test in passively coping (vulnerable rats) to the level of actively coping (resilient rats). As expected, inhibition of orexin neurons before each defeat had no effect on subsequent behavior in resilient rats, as our experiments indicate they already express very low levels of orexins. Thus, inhibiting orexin action during the last 3 d of social defeat increased social interaction and decreased depressive-like behaviors specifically in the vulnerable population of rats, thereby promoting resilience. This indicates that dampened orexin function under conditions of stress contributes to resilience to social defeat.

Prepro-orexin expression was lower in resilient rats compared with vulnerable rats by both in situ radiolabeling and qPCR methods. This phenotype was stable in multiple cohorts of rats, immediately after repeated social defeat, as well as after several additional behavioral tests. We cannot determine if prepro-orexin expression was lower in resilient rats before social stress or as a consequence of social stress; thus, it is possible it is a preexisting difference. A previous study demonstrated that control female rats had higher orexin expression than male rats, and as a result, females had persistent HPA activation in response to repeated restraint stress and were not able to habituate as fully as males (Grafe et al., 2017a). Just as females had higher levels of orexins before the stressor, and thus were inherently different from males, perhaps actively coping (resilient) rats are inherently different from passively coping (vulnerable) rats before social defeat occurs. In this respect, pre-existing differences in orexin expression impact future responses to stress. On the other hand, perhaps orexin function is also decreased with repeated exposure to social defeat in rats that become resilient to defeat; this is known to occur after repeated restraint stress (Grafe et al., 2017b). Currently, we are only able to measure cerebrospinal fluid levels of orexins terminally, and plasma levels of orexins are not a reliable indication of central orexin activity; thus, we cannot directly determine whether this difference in orexin expression predates exposure to stress.

Based on these data, we hypothesized that lower levels of orexin contribute to resilience to repeated social stress. After rats established active and passive coping phenotypes, orexins were inhibited by DREADDs in subsequent days of social defeat. Behavior was examined in both the social interaction and forced swim tests to determine how orexin action during defeat affects subsequent anxietylike and depressive-like behaviors. Our results first demonstrated that vehicle-treated actively coping rats spent more time socially interacting than passively coping rats, replicating a previous finding (Wood et al., 2010). Orexin inhibition during the last $3 \mathrm{~d}$ of defeat increased the amount of time passively coping rats spent interacting 
with a stimulus rat, with total interaction time at a level comparable to that of actively coping rats. This result is consistent with earlier studies in which central injections of orexins produced anxiety-like behaviors in the lightdark test and elevated plus maze (Suzuki et al., 2005; Li et al., 2010; Avolio et al., 2011). As expected, inhibition of orexins in resilient rats during social defeat did not further increase their social interaction time, likely because resilient rats already express low levels of orexins. In sum, orexins promote anxiety behaviors, and dampening orexin action throughout repeated stress allows rats that are initially vulnerable to exhibit the resilient phenotype.

The increase in social interaction observed in CNOtreated passively coping rats was independent of the total amount of movement in the social interaction chamber. As orexins have been shown to modulate spontaneous physical activity (Kotz et al., 2002), it is important to note that the increase in social interaction was not accompanied by an increase in activity; thus, it is a socially specific behavioral result and not an effect on global arousal. Moreover, the orexin manipulation took place only during the last $3 \mathrm{~d}$ of social defeat, and not during this social interaction test; thus, short-term action of CNO treatment did not confound our results. However, our data indicate that $\mathrm{CNO}$ treatment on days $6-8$ of social defeat can cause long-lasting changes in prepro-orexin mRNA expression, which then leads to changes in social interaction behavior.

In the FST, vehicle-treated passively coping rats spent significantly more time immobile than control rats, replicating a previous finding that passive coping during social defeat leads to depressive-like behavior (Wood et al., 2010). DREADDs-mediated inhibition of orexin neurons before three social defeat exposures reduced percentage time spent immobile in the vulnerable rats. Hence, increased orexin action may contribute to depressive-like behavior. However, we found that repeated CNO treatment increased immobility in control, nonstressed animals. Thus, inhibiting orexins in nonstress conditions increases depressive-like behavior. Our data show that prepro-orexin expression does not differ between vehicleand CNO-treated control (nonstressed) animals, so this cannot explain the differences in percentage immobility in the FST. It is possible that other measures of orexin function, such as neuronal activation, may differ between vehicle- and CNO-treated control animals, explaining these differences in behavior. Ultimately, the effect of inhibiting orexins on immobility is dependent on whether the animal is stressed; different brain circuits involving orexins may be activated in these different conditions, explaining the opposing behaviors.

The link between the orexinergic system and depression remains equivocal, as clinical models report conflicting results. Specifically, different studies indicate that either hypoactivity (Brundin et al., 2007; Ito et al., 2008) or hyperactivity (Salomon et al., 2003; von der Goltz et al., 2011) of the orexinergic system is associated with MDD (Brundin et al., 2007; Lutter et al., 2008). Some inconsistencies may result from limitation of methods, as orexin levels in plasma are close to the resolving limit of radioimmunoassay (Chen et al., 2015a). Moreover, whether measures of orexin A in plasma or cerebrospinal fluid are physiologically meaningful and can act as proxy for orexin system activity remains to be established. However, a recent preclinical study provided a causal link between orexins and depressive-like behavior: pharmacological blockade of the orexin system during unpredictable chronic mild stress reduced subsequent immobility in the tail suspension test (Nollet et al., 2012). This result is consistent with our findings in that inhibition of orexins during stress decreases subsequent depressive-like behavior. As expected, inhibition of orexins in actively coping rats during the last $3 \mathrm{~d}$ of social defeat did not further decrease immobility, as our results indicate that actively coping (resilient) rats already express very low levels of orexins. Together, these data suggest that low levels of orexins may be a biomarker to predict resilience to stress and thus, a lower likelihood of developing depression.

Rats that displayed passive coping spent less time active (mostly due to a decrease in swimming) in the FST than control rats. However, blocking orexin action before three social defeat exposures appeared to increase both swimming and climbing in passively coping rats. Independently, these two measures were not significantly increased with CNO treatment. Specifically, CNO treatment increased the sum of these two behaviors together, measured as total activity. Swimming and climbing are known to be mediated by serotonin and norepinephrine, respectively, as antidepressants targeting these neurotransmitters can selectively increase these behaviors (Bogdanova et al., 2013). Indeed, it is known that orexins have direct connections with both serotoninergic and noradrenergic neurons to regulate sleep/ wakefulness, thus, it makes sense that manipulating orexins may affect swimming and climbing behavior (Tabuchi et al., 2013; Zitnik, 2016). However, the effect of manipulating orexins on these behaviors appears to be dependent on whether the animal is stressed: inhibiting orexins in a control animal decreases activity (and increases immobility), whereas inhibiting orexins in a socially defeated rat increases activity (and decreases immobility). Thus, repeated stress must change the way these neurotransmitters interact with orexins.

Recent findings have indicated that a high dose $(10 \mathrm{mg} /$ $\mathrm{kg}$ ) of CNO may allow for nonspecific effects of the metabolite clozapine on behavior (Gomez et al., 2017). Particularly, converted clozapine could have effects on the DREADDs or, if the levels are high enough, on endogenous clozapine binding sites as well. Moreover, another study found that $5-\mathrm{mg} / \mathrm{kg}$ doses of CNO have behavioral effects in LongEvans rats not expressing DREADDs (MacLaren et al., 2016). We tested whether the lower dose of CNO (2 mg/kg) used in the present studies had nonspecific behavioral effects. We found that CNO treatment in non-DREADDsexpressing rats did not cause significant effects in the social interaction test or Porsolt forced swim test. Thus, we can conclude that the effects of DREADDs we observed in our studies were not due to actions of CNO or its metabolites but to DREADDs-induced inhibition of orexins.

The brain regions in which orexins act during stress to regulate subsequent anxiety-like and depressive-like behaviors are not fully elucidated. However, there are many 
key brain areas that likely play a role. For example, orexins have dense projections to brain areas relevant to anxietyand depressive-like behaviors such as the paraventricular nucleus of the thalamus (PVT), locus coeruleus, prefrontal cortex, dorsal raphe, hippocampus, and amygdala (Peyron et al., 1998). Previous studies have demonstrated that orexins act in the PVT to induce anxiety-like behavior ( $\mathrm{Li}$ et al., 2010; Heydendael et al., 2011, 2013). Another study found that orexin 1 receptors in the amygdala regulate stress-induced depressive-like behavior (Arendt et al., 2013). Other experiments indicate that orexin interaction with the dorsal raphe may be important for regulation of stress-induced depressive-like behavior (Brown et al., 2001; Muraki et al., 2004). Future studies should further examine the role of specific brain regions where orexins may be acting to promote resilience and identify genes mediating these orexin effects.

Because orexins are known to underlie arousal and appetite, it is possible that inhibition of these neuropeptides with DREADDs affected these physiologic parameters and, thus, may have influenced our results (Sakurai, 2014). For example, if inhibiting orexin action allowed animals to sleep more, perhaps this could have subsequently decreased anxiety-like or depressive-like behavior. While our results show that there were no changes in general arousal between treatment groups in terms of total movement during behavioral tests, measuring sleep parameters after orexin manipulation may provide more insight. Additionally, though we did not measure food intake throughout the study, there were no differences in body weight gain between vehicle- and CNO-treated rats, indicating that changes in appetite and food intake did not have a significant effect on the present results.

The results from this study demonstrate that orexin expression is lower in rats resilient to social defeat stress. To provide a causal link between decreased orexins and resilience, we inhibited orexins during the last $3 \mathrm{~d}$ of social defeat stress and reversed the negative behavioral effects of social defeat in previously vulnerable rats. These findings highlight orexins as previously uncharacterized substrates of resilience.

\section{References}

Alexander GM, Rogan SC, Abbas Al, Armbruster BN, Pei Y, Allen JA, Nonneman RJ, Hartmann J, Moy SS, Nicolelis MA, McNamara JO, Roth BL (2009) Remote control of neuronal activity in transgenic mice expressing evolved $G$ protein-coupled receptors. Neuron 63:27-39. CrossRef

Arendt DH, Ronan PJ, Oliver KD, Callahan LB, Summers TR, Summers CH (2013) Depressive behavior and activation of the orexin/ hypocretin system. Behav Neurosci 127:86-94. CrossRef

Armbruster BN, Li X, Pausch MH, Herlitze S, Roth BL (2007) Evolving the lock to fit the key to create a family of $G$ protein-coupled receptors potently activated by an inert ligand. Proc Natl Acad Sci U S A 104:5163-5168. CrossRef

Avolio E, Alò R, Carelli A, Canonaco M (2011) Amygdalar orexinergic-GABAergic interactions regulate anxiety behaviors of the Syrian golden hamster. Behav Brain Res 218:288-295. CrossRef

Berridge CW, España RA (2005) Hypocretins: waking, arousal, or action? Neuron 46:696-698.

Billings AG, Moos RH (1984) Coping, stress, and social resources among adults with unipolar depression. J Pers Soc Psychol 46: 877-891. CrossRef
Bogdanova OV, Kanekar S, D'Anci KE, Renshaw PF (2013) Factors influencing behavior in the forced swim test. Physiol Behav 118: 227-239.

Brown RE, Sergeeva O, Eriksson KS, Haas HL (2001) Orexin A excites serotonergic neurons in the dorsal raphe nucleus of the rat. Neuropharmacology 40:457-459. CrossRef

Brundin L, Björkqvist M, Petersén A, Träskman-Bendz L (2007) Reduced orexin levels in the cerebrospinal fluid of suicidal patients with major depressive disorder. Eur Neuropsychopharmacol 17: 573-579. CrossRef

Chang $\mathrm{H}$, Saito T, Ohiwa N, Tateoka M, Deocaris CC, Fujikawa T, Soya $\mathrm{H}(2007)$ Inhibitory effects of an orexin-2 receptor antagonist on orexin A- and stress-induced ACTH responses in conscious rats. Neurosci Res 57:462-466. CrossRef

Chen Q, de Lecea L, Hu Z, Gao D (2015a) The hypocretin/orexin system: an increasingly important role in neuropsychiatry. Med Res Rev 35:152-197.

Chen RJ, Kelly G, Sengupta A, Heydendael W, Nicholas B, Beltrami S, Luz S, Peixoto L, Abel T, Bhatnagar S (2015b) MicroRNAs as biomarkers of resilience or vulnerability to stress. Neuroscience 305:36-48. CrossRef Medline

Chen X, Wang H, Lin Z, Li S, Li Y, Bergen HT, Vrontakis ME, Kirouac GJ (2013) Orexins (hypocretins) contribute to fear and avoidance in rats exposed to a single episode of footshocks. Brain Struct Funct 219:2103-2118.

de Lecea L, Kilduff TS, Peyron C, Gao X, Foye PE, Danielson PE, Fukuhara C, Battenberg EL, Gautvik VT, Bartlett FS, Frankel WN, van den Pol AN, Bloom FE, Gautvik KM, Sutcliffe JG (1998) The hypocretins: hypothalamus-specific peptides with neuroexcitatory activity. Proc Natl Acad Sci U S A 95:322-327. CrossRef

Ehlert U, Gaab J, Heinrichs M (2001) Psychoneuroendocrinological contributions to the etiology of depression, posttraumatic stress disorder, and stress-related bodily disorders: the role of the hypothalamuspituitary-adrenal axis. Biol Psychol 57:141-152. Medline

Engel GL, Schmale AH (1972) Conservation-withdrawal: a primary regulatory process for organismic homeostasis. Ciba Found Symp 8:57-75.

Farrell MS, Roth BL (2013) Pharmacosynthetics: reimagining the pharmacogenetic approach. Brain Res 1511:6-20.

Finnell JE, Lombard CM, Melson MN, Singh NP, Nagarkatti M, Nagarkatti P, Fadel JR, Wood CS, Wood SK (2017a) The protective effects of resveratrol on social stress-induced cytokine release and depressive-like behavior. Brain Behav Immun 59:147-157. CrossRef

Finnell JE, Lombard CM, Padi AR, Moffitt CM, Wilson LB, Wood CS, Wood SK (2017b) Physical versus psychological social stress in male rats reveals distinct cardiovascular, inflammatory and behavioral consequences. PLoS One 12:e0172868. CrossRef

Folkman S, Lazarus RS (1980) An analysis of coping in a middle-aged community sample. J Health Soc Behav 21:219-239. CrossRef

Furlong TM, Vianna DML, Liu L, Carrive P (2009) Hypocretin/orexin contributes to the expression of some but not all forms of stress and arousal. Eur J Neurosci 30:1603-1614. CrossRef

Gomez JL, Bonaventura J, Lesniak W, Mathews WB, Sysa-Shah P, Rodriguez LA, Ellis RJ, Richie CT, Harvey BK, Dannals RF, Pomper MG, Bonci A, Michaelides M (2017) Chemogenetics revealed: DREADD occupancy and activation via converted clozapine. Science 357:503-507. CrossRef

Grafe LA, Cornfeld A, Luz S, Valentino R, Bhatnagar S (2017a) Orexins mediate sex differences in the stress response and in cognitive flexibility. Biol Psychiatry 81:683-692. CrossRef Medline

Grafe LA, Eacret D, Luz S, Gotter AL, Renger JJ, Winrow CJ, Bhatnagar S (2017b) Orexin 2 receptor regulation of the hypothalamic-pituitary-adrenal (HPA) response to acute and repeated stress. Neuroscience 348:313-323. CrossRef

Hasegawa E, Yanagisawa M, Sakurai T, Mieda M (2014) Orexin neurons suppress narcolepsy via 2 distinct efferent pathways. J Clin Invest 124:604-616. CrossRef 
Heydendael W, Sengupta A, Beck S, Bhatnagar S (2013) Optogenetic examination identifies a context-specific role for orexins/hypocretins in anxiety-related behavior. Physiol Behav 130:182-190.

Heydendael W, Sharma K, lyer V, Luz S, Piel D, Beck S, Bhatnagar $S$ (2011) Orexins/hypocretins act in the posterior paraventricular thalamic nucleus during repeated stress to regulate facilitation to novel stress. Endocrinology 152:4738-4752. CrossRef

Ito N, Yabe T, Gamo Y, Nagai T, Oikawa T, Yamada H, Hanawa T (2008) I.c.v. administration of orexin-A induces an antidepressivelike effect through hippocampal cell proliferation. Neuroscience 157:720-732. CrossRef

Jászberényi M, Bujdosó E, Pataki I, Telegdy G (2000) Effects of orexins on the hypothalamic-pituitary-adrenal system. J Neuroendocrinol 12:1174-1178. Medline

Johnson PL, Molosh A, Fitz SD, Truitt WA, Shekhar A (2012) Orexin, stress, and anxiety/panic states. Prog Brain Res 198:133-161.

Koolhaas JM, Korte SM, De Boer SF, Van Der Vegt BJ, Van Reenen CG, Hopster H, De Jong IC, Ruis MA, Blokhuis HJ (1999) Coping styles in animals: current status in behavior and stress-physiology. Neurosci Biobehav Rev 23:925-935. CrossRef

Kotz CM, Teske JA, Levine JA, Wang C (2002) Feeding and activity induced by orexin $A$ in the lateral hypothalamus in rats. Regul Pept 104:27-32. CrossRef

Kuru M, Ueta Y, Serino R, Nakazato M, Yamamoto Y, Shibuya I, Yamashita H (2000) Centrally administered orexin/hypocretin activates HPA axis in rats. Neuroreport 11:1977-1980. CrossRef

Kuwaki T (2011) Orexin links emotional stress to autonomic functions. Auton Neurosci 161:20-27.

Le T, Liang Z, Patel H, Yu MH, Sivasubramaniam G, Slovitt M, Tanentzapf G, Mohanty N, Paul SM, Wu VM, Beitel GJ (2006) A new family of Drosophila balancer chromosomes with a w-dfdGMR yellow fluorescent protein marker. Genetics 174:2255-2257. CrossRef

Li Y, Li S, Wei C, Wang H, Sui N, Kirouac GJ (2010) Orexins in the paraventricular nucleus of the thalamus mediate anxiety-like responses in rats. Psychopharmacology 212:251-265. CrossRef

Lucki I (1997) The forced swimming test as a model for core and component behavioral effects of antidepressant drugs. Behav Pharmacol 8:523-532. CrossRef

Lutter M, Krishnan V, Russo SJ, Jung S, McClung CA, Nestler EJ (2008) Orexin signaling mediates the antidepressant-like effect of calorie restriction. J Neurosci 28:3071-3075. CrossRef

MacLaren DAA, Browne RW, Shaw JK, Krishnan Radhakrishnan S, Khare P, España RA, Clark SD (2016) Clozapine N-oxide administration produces behavioral effects in Long-Evans rats: implications for designing DREADD experiments. eNeuro 3:0219-16. CrossRef

McCall JG, Al-Hasani R, Siuda ER, Hong DY, Norris AJ, Ford CP, Bruchas MR (2015) CRH engagement of the locus coeruleus noradrenergic system mediates stress-induced anxiety. Neuron 87: 605-620. CrossRef

McEwen BS, Stellar E (1993) Stress and the individual. Mechanisms leading to disease. Arch Intern Med 153:2093-2101.

Messina G, Dalia C, Tafuri D, Monda V, Palmieri F, Dato A, Russo A, De Blasio S, Messina A, De Luca V, Chieffi S, Monda M (2014) Orexin-A controls sympathetic activity and eating behavior. Front Psychol 5:997. CrossRef

Miczek KA (1979) A new test for aggression in rats without aversive stimulation: differential effects of d-amphetamine and cocaine. Psychopharmacology 60:253-259. CrossRef

Muraki Y, Yamanaka A, Tsujino N, Kilduff TS, Goto K, Sakurai T (2004) Serotonergic regulation of the orexin/hypocretin neurons through the 5-HT1A receptor. J Neurosci 24:7159-7166.

Nollet M, Gaillard P, Tanti A, Girault V, Belzung C, Leman S (2012) Neurogenesis-independent antidepressant-like effects on behavior and stress axis response of a dual orexin receptor antagonist in a rodent model of depression. Neuropsychopharmacology 37: 2210-2221. CrossRef

Paxinos G, Watson C (1998) The Rat Brain in Stereotaxic Coordinates. Academic Press.
Pearson-Leary J, Eacret D, Chen R, Takano H, Nicholas B, Bhatnagar S (2017) Inflammation and vascular remodeling in the ventral hippocampus contributes to vulnerability to stress. Transl Psychiatry 7:e1160. CrossRef

Peyron C, Tighe DK, van den Pol AN, de Lecea L, Heller HC, Sutcliffe JG, Kilduff TS (1998) Neurons containing hypocretin (orexin) project to multiple neuronal systems. J Neurosci 18:9996-10015.

Reynolds A, Richards G, de la Iglesia B, Rayward-Smith V (1992) Clustering rules: a comparison of partitioning and hierarchical clustering algorithms. J Math Model Algorithms 5:475-504. CrossRef

Sakurai T, et al. (1998) Orexins and orexin receptors: a family of hypothalamic neuropeptides and $\mathrm{G}$ protein-coupled receptors that regulate feeding behavior. Cell 92:573-585.

Sakurai T (2014) The role of orexin in motivated behaviours. Nat Rev Neurosci 15:719-731. CrossRef

Salomon RM, Ripley B, Kennedy JS, Johnson B, Schmidt D, Zeitzer JM, Nishino S, Mignot E (2003) Diurnal variation of cerebrospinal fluid hypocretin-1 (Orexin-A) levels in control and depressed subjects. Biol Psychiatry 54:96-104. CrossRef

Southwick SM, Vythilingam M, Charney DS (2005) The psychobiology of depression and resilience to stress: implications for prevention and treatment. Annu Rev Clin Psychol 1:255-291. CrossRef Medline

Spinazzi R, Andreis PG, Rossi GP, Nussdorfer GG (2006) Orexins in the regulation of the hypothalamic-pituitary-adrenal axis. Pharmacol Rev 58:46-57.

Strawn JR, Pyne-Geithman GJ, Ekhator NN, Horn PS, Uhde TW, Shutter L. a, Baker DG, Geracioti TD (2010) Low cerebrospinal fluid and plasma orexin-A (hypocretin-1) concentrations in combatrelated posttraumatic stress disorder. Psychoneuroendocrinology 35:1001-1007. CrossRef

Suzuki M, Beuckmann CT, Shikata K, Ogura H, Sawai T (2005) Orexin-A (hypocretin-1) is possibly involved in generation of anxiety-like behavior. Brain Res 1044:116-121. CrossRef

Tabuchi S, Tsunematsu T, Kilduff TS, Sugio S, Xu M, Tanaka KF, Takahashi S, Tominaga M, Yamanaka A (2013) Influence of inhibitory serotonergic inputs to orexin/hypocretin neurons on the diurnal rhythm of sleep and wakefulness. Sleep 36:1391-1404.

Veenema AH, Meijer OC, de Kloet ER, Koolhaas JM (2003) Genetic selection for coping style predicts stressor susceptibility. J Neuroendocrinol 15:256-267. CrossRef

von der Goltz C, Koopmann A, Dinter C, Richter A, Grosshans M, Fink T, Wiedemann K, Kiefer F (2011) Involvement of orexin in the regulation of stress, depression and reward in alcohol dependence. Horm Behav 60:644-650. CrossRef

Winsky-Sommerer R, Boutrel B, de Lecea L (2005) Stress and arousal: the corticotrophin-releasing factor/hypocretin circuitry. Mol Neurobiol 32:285-294. CrossRef

Winsky-Sommerer R, Yamanaka A, Diano S, Borok E, Roberts AJ, Sakurai T, Kilduff TS, Horvath TL, de Lecea L (2004) Interaction between the corticotropin-releasing factor system and hypocretins (orexins): a novel circuit mediating stress response. J Neurosci 24:11439-11448.

Wood SK, Bhatnagar S (2015) Resilience to the effects of social stress: evidence from clinical and preclinical studies on the role of coping strategies. Neurobiol Stress 1:164-173. CrossRef

Wood SK, Walker HE, Valentino RJ, Bhatnagar S (2010) Individual differences in reactivity to social stress predict susceptibility and resilience to a depressive phenotype: role of corticotropinreleasing factor. Endocrinology 151:1795-1805. CrossRef

Wood SK, Wood CS, Lombard CM, Lee CS, Zhang X-Y, Finnell JE, Valentino RJ (2015) Inflammatory factors mediate vulnerability to a social stress-induced depressive-like phenotype in passive coping rats. Biol Psychiatry 78:38-48.

Yehuda R (2000) Biology of posttraumatic stress disorder. J Clin Psychiatry 61: 14-21.

Yehuda R, Teicher MH, Levengood RA, Trestman RL, Siever LJ (1994) Circadian regulation of basal cortisol levels in posttraumatic stress disorder. Ann N Y Acad Sci 746:378-380. CrossRef

Zitnik GA (2016) Control of arousal through neuropeptide afferents of the locus coeruleus. Brain Res 1641:338-350. CrossRef 